\title{
THE LIKELY ORGANIZATIONAL ORDER OF ADVANCED INTELLIGENCES
}

\author{
Peter Schenkel \\ Centro Internacional de Estudios Superiores de Comunicacion \\ para America Latina \\ Cas. 6064 CCI, Quito, Ecuador
}

\begin{abstract}
Summary
Civilizations, highly advanced in science and technology, are bound to possess also a highly refined organizational order. Otherwise they would not have survived. The human analogy supports this proposition. Though still beset by intra-species conflict, our world is already pregnant with tendencies moving it toward a global political and economic order. Contact with a superior extraterrestrial intelligence would therefore serve mankind not only as a thrilling scientific but also as a powerful organizational and cultural stimulus.
\end{abstract}

